Working Paper \#03-41 (10)

Business Economics Series

September 2003
Sección de Organización de Empresas de Getafe

Universidad Carlos III de Madrid

Calle Madrid, 123

28903 Getafe (Spain)

Fax (34) 916245707

\title{
TEMPORARY HELP AGENCIES AND OCCUPATIONAL MOBILITY*
}

\author{
J. Ignacio García-Pérez ${ }^{1}$ and Fernando Muñoz-Bullón ${ }^{2}$
}

\begin{abstract}
This paper focuses upon the effect of Temporary Help Agencies (THAs) on occupational mobility through a comparison of the job-to-job upgrading chances of THA and non-THA workers. A screening approach to the role of these labor "brokers" suggests that agency workers can expect greater upgrading chances between two different occupations. Results obtained from a sample of Spanish workers show that working through these intermediaries allows workers in intermediate occupational levels to avoid occupational demotions more easily than non-THA ones. Moreover, THAs improve the probability for high-skilled workers of achieving a permanent contract. The empirical analysis demonstrates that the existence of self-selection is an important explanation for increased occupational mobility among THA workers in Spain.
\end{abstract}

Keywords: temporary help agencies; screening; self-selection; switching models.

* This work has benefited from financial support by CICYT SEC2002-04471. We would like to express our gratitude to the Spanish Ministry of Labor for providing us with the database, to Dörte Dömeland-Narváez, Silvio Rendón and Ernesto Villanueva for all their help, and to seminar participants at FEDEA, U. Pompeu Fabra, U. Málaga, U. del País Vasco, the III International Workshop on Human Resources Management (Seville, 2001), the XI EALE Annual Conference and the 16th Annual Congress of the European Economics Association for their comments. The usual disclaimer applies.

${ }^{1}$ centrA, C/ Bailen, 50 - 41001 Seville (Spain); jigarcia@ fundacion-centra.org

${ }^{2}$ Universidad Carlos III, C/Madrid 126-Getafe (Madrid), 28903 (Spain); fmunoz@emp.uc3m.es 


\section{Introduction}

Temporary Help Agencies ${ }^{1}$ (THAs) offer employment contracts of a limited duration to jobseekers and assign them to client firms wishing to hire them to perform jobs of a temporary nature. The Spanish labour market reform in 1994 — which for the first time allowed those agencies to operate - has focused attention on these labour market intermediaries and their role in the functioning of this labour market, the one with the highest unemployment rate in Europe (almost 20\% on average throughout the nineties). From then on, THA contracting has become a growing area, actually accounting for almost $16 \%$ of the total number of temporary contracts in Spain (see Table 1). Furthermore, the percentage of temporary contracts in Spain is the highest one in Europe: more than $30 \%$ of total workers throughout the nineties. Hence, the incidence of THAs in this labour market is of particular interest not only for politicians but also for labour economists.

Attempts to analyze this phenomenon are by no means lacking although THA work has been one of the most heated debates of recent years. Yet, research has not explained the role that these agencies play in relation to workers' careers. Career prospects of agency workers are either assumed or considered as a by-product of the pernicious social reality that these agencies are supposedly hiding. Indeed, the opponents to Temporary Help Agencies present as their main argument that the existence of these agencies exacerbates the inherent insecurities of the labour market $^{2}$.

Unlike this line of research, our main argument is that this intermediary may be viewed as a screening device within the structuring of the employment relationship. We focus on the effects of THA work on occupational mobility and compare them to non-THA workers. Our main argument is that THAs offer a unique screening device that matches the individual with the most appropriate skill-level to the job in question. This can help relatively high-qualified workers and, hence, they may use THAs as a way of signalling their quality, given the likely prospect of obtaining higher chances of upward occupational mobility through this signalling

\footnotetext{
${ }^{1}$ Several other terms are commonly used for the companies that employ individuals to send them out to other worksites at other companies: staffing companies (the term preferred by the companies themselves), agencies (the traditional term), and temporary help supply companies or services (the term used by the U.S. Bureau of Labor Statistics).

${ }^{2}$ Common criticisms are that (1) THA workers only receive brief assignments interspersed with relatively long periods of unemployment (Bronstein, 1991); (2) that not only are THA workers paid less than core workers for working at similar types of jobs, but also that their chances of obtaining employee benefits are less than those for traditional core workers (Emerson, 1988; Moberly, 1987); (3) that such a situation may create uncertainty and greater economic risk for these workers (Blank, 1998); and (4) that extensive reliance on THA workers may create two classes of employees: permanent workers with relatively secure, high-paying employment and THA workers (along with temporary workers in general) who have only sporadic, low-paid work (Mangum et al., 1985).
} 
process. Thus, agency workers may be able to advance more quickly in their careers (in terms of both their occupational level and the type of contract held). It is with this issue that the present analysis is concerned. To conduct such an analysis, we investigate the question of the self-selection process underlying the decision to address to a THA to find a job. Those who choose to do so may be more able and/or more motivated than those who choose to rely on their own. Moreover, it may well be the case that workers apply to THAs only after direct methods to find a job have proved fruitless. Hence, self-selection is an important issue for our empirical approach which will be based on a switching model for occupational mobility. We specifically ask two questions: (i) Had they chosen not to address to a THA, what would be their performance?, and (ii) What would be the performance of non-THA workers had they decided to work through the agency?

To do so, we use a a recent data source, Social Security records, which provides complete employment histories of a sample of workers - some of whom work through THAs. We find support for a positive self-selection of THA workers belonging to the highest occupational category compared to non-THA individuals. Our empirical results show that highly qualified THA individuals would have enjoyed a much lower probability of access to permanent contracts had they chosen not to address to the agency. Our results also give support to a story of negative self-selection for THA individuals in the lowest occupational category. Individuals engaged through THA in this occupational group would have shown better performance - both in terms of access to permanent contracts and of avoiding occupational demotion - had they decided not to address to this intermediary. Finally, the effect of working through a THA for workers in an intermediate occupational level basically consists of a lower likelihood of having to accept new jobs with lower skill requirements.

To our knowledge, this is the first systematic analysis of career prospects associated to THA work. This important aspect of the labor market has been virtually ignored in the economic literature, mainly due to the absence of accurate databases to fill this gap. Intermediation of THA may affect worker employment prospects through three different ways: the time the worker needs to find a job, the quality of the job found or the future career prospects the THA is offering to the worker. The effect of THAs over the duration of both employment and unemployment spells is analyzed in García-Pérez and Muñoz-Bullón (2003). They find that although job tenure through THAs is lower than without these intermediaries, the main advantage offered for workers is that unemployment spells in between two jobs is shorter than for non-THA workers ${ }^{3}$. However, it is the latter issue, the

\footnotetext{
${ }^{3}$ In spite of the absence of data on wages, our dataset offers another signal of the quality of the job found: the proportion of workers in an occupational level higher than the one in the first job of their work history is $25.82 \%$ for no-THA workers whereas it is $35.34 \%$ through THAs.
} 
one investigated in the present paper, which we consider to be the most relevant: the future career prospects of THA workers. This is also the first study on such an issue to take explicitly into account the possible existence of self-selection into THA-intermediated work by using a switching model. In addition, since upward movements along the occupational trajectory are generally accompanied by appropriate wage increments, our study is related to the extent to which workers engaged through these intermediaries have improved chances of increasing their labour earnings over time ${ }^{4}$.

We organize the paper as follows. Firstly, we briefly offer some data on THA contracting in Spain, revise the motivations most frequently cited behind this phenomenon and present the predictions upon which the empirical research is conducted. Secondly, we describe the data and the econometric model used in our analysis. Thirdly, we present the empirical results. The last section puts forward our main conclusions.

\section{The THA industry: A brief background}

In Spain, THAs have only been under formal government regulation since the 1994 labour market reform. As labour market intermediaries, they connect labour demand and labour supply. Once hired by the THA, the worker is sent to render her services to a client firm, which agrees upon the provision of the worker by the THA. There exists a standard labour contract for a limited duration between the THA and the worker, and a commercial contract (called assignment contract) between the THA and the firm. Therefore, workers remain on the THA's payroll while working for the client firm, i.e., these workers become part of a triangular relationship between the worker, the THA and the firm in which the work is performed (see Muñoz-Bullón, 2002, or Muñoz-Bullón and Rodes, 2003).

From the point of view of the worker, recent studies show that the large majority of workers choose a THA as a means to find permanent work and to supplement income during job search, while a minority prefer to stay as THA workers (Cohany, 1996 and 1998; Steinberg, 1994 and 1998). In addition, it is reasonable to think that some individual job applicants would have fewer opportunities to obtain a range of potential jobs by their own (Belous, 1989), and that some of them would appreciate the greater flexibility in scheduling that THA employment offers (Blank, 1998).

Client firms adduce a variety of reasons when asked why they resort to agency workers. The first reason has to do with THA employment as a flexibility device in the face of fluctuating product demand. In addition, some companies want to

Hence, workers are not being underclassified when they begin working through THAs.

${ }^{4}$ In any case, due to the absence on wages, this paper does not ask the question related to the size of the returns to occupational mobility in terms of earnings and subsequent wage growth. 
buffer core employees from business fluctuations, when the production process is discontinued or plants or offices shut down. There is little doubt that agency and other forms of contingent employment do give managers this flexibility (Abraham, 1990; Blank, 1998; Houseman, 1997; Nollen, 1996). The second reason has to do with a desire to reduce labour costs (especially fixed labour costs). If temporary workers are paid less than core employees, labour compensation goes down. In addition, client firms want to ease management tasks (administration, paper work and personnel services).

Those demand-side motivations have constituted the main focus in the literature of THAs. This popular view has found its way into much of the academic literature, where it is presented as a major reason for the rapid growth of contingent work (Abraham, 1988; Davis-Blake and Uzzi, 1993; Tsui, Pearce, Porter and Hite, 1995). Although obviously useful and important, these explanations are still a matter of controversy, since hard evidence on this issue is certainly difficult to come by. More importantly, although we are not questioning those studies, we regard them as incomplete. THAs not only provide "just-in-time" or contingent workers to firms under unplanned circumstances. Some firms outsource all the screening processes of some categories of workers to these agencies, so that every potential candidate must start working initially through a THA. Indeed, recent surveys indicate that client firms value THA contracting as a device to prospect among temporary workers for candidates who could be recruited to fill vacancies on a permanent basis (Ballantine and Ferguson, 1999; Houseman, 1997). In these cases, THA employment will be basically determined by the incidence of the asymmetric information problem which both the THA screening services and the initial assignment through the THA (which, indeed, consists of a "probationary" assignment) are meant to solve. Hence, client firms will be able to realize savings in labour costs by not having to recruit or select candidates (tasks for which they may not have time or expertise).

How may THA work affect individual's opportunity for career advancement and future wages? Suppose that two otherwise identical individuals end up working in the same job of the same firm, but one of them placed by a THA and the other not. Will their career paths differ as a result of the different hiring procedures they have gone through? ${ }^{5}$ To answer this question, we can consider an economy in which neither individuals — who differ in the comparative skills with which they can perform different jobs - nor the market knows workers' abilities, and where, in addition, firms act competitively and no intermediation by THAs were possible. In this context, given that promoting the individual constitutes a signal of high ability, the actual employer — who knows worker's ability after the first employment period - may prefer to inefficiently underpromote some of their

\footnotetext{
${ }^{5}$ The term 'path' refers to the ability to increase one's labor earnings over time.
} 
employees. Otherwise, the employer would have to pay a too high wage to the promoted workers, since competition for workers would lead the employer to pay their expected productivity given the assignment (Waldman, 1984).

On the contrary, in a labour market with vertically-differentiated agents -i.e., good workers are good for any task - THAs act as a screening device available to firms. ${ }^{6}$ They will only accept workers who are sufficiently good, so that the most productive individuals will be identified. Becoming a THA worker becomes, thus, a publicly available part of the individual's employment history: the ability certification by the THA reveals worker's quality and - as a result of the attenuation of information asymmetry among employers in the economy - the previously commented missasignment of workers to tasks can be confined. If the actual employer intended to underpromote some of the workers - exploiting, again, the private information on workers' true ability level - then the THA would have incentives to reassign the temporary worker to another firm, since other firms would bid for worker's services.

Available qualitative evidence suggests, indeed, that client firms especially appreciate the fact that THAs assume responsibility for staff selection, an often complex task which is all the more burdensome when short-term recruitment is involved (Bronstein, 1991). Indeed, in some sectors, THAs represent the primary way to auditing and hiring new workers (Autor, 2001). In this same vein, Houseman (1997) found that one-fifth of client firms in the US addressed to THAs as a source for future recruitment. ${ }^{7}$ Thus, evidence confirms the notion that THAs generate employees with high productivity, suggesting that client firms regard agency workers as being more "reliable" than direct applications from prospective employees. In particular, hiring THA workers to monitor them and then to offer permanent positions only to those who perform well seems to have become a common strategy by client firms. This pre-selection role is likely to be an important determinant for high-skilled individuals to address to THAs. As opposed to lowskilled workers, they will face incentives to collect the gains from THA-work in terms of occupational mobility. Even though the majority of THA contracts are based on unskilled jobs (59 per cent in 1998) in Spain, THA workers are not in general badly educated. In 1998, $76 \%$ of THA contracts were held by individuals in possession of secondary or higher education, while only $64 \%$ of total registered contracts held this qualification level. ${ }^{8}$ Therefore, one will expect this cohort of

\footnotetext{
${ }^{6}$ Alternatively, in a labor market with costly search and horizontally-differentiated agents (i.e., with match-specific heterogeneity) THAs may also help to achieve an efficient assignment of workers to jobs.

${ }^{7}$ The use of fixed-term labor contracts in general has also been presented as a source of candidates for permanent jobs. For instance, Abraham (1988), found that 23 percent of firms that used "flexible" forms of employment intended to identify adequate candidates for permanent jobs

${ }^{8}$ These figures come from the Spanish Ministry of Labor's statistical bulletin. Similarly,
} 
positively-selected THA individuals to be promoted out of low-level occupations and into higher-level occupations. Moreover, they can be expected to advance more quickly in their careers.

However, people with lower than average skills will be more likely not to address to a THA because only the relatively more able will find it worthwhile to work through the agency. Among this pool of negatively-selected THA workers, other motivations rather than the screening services provided by the THA will be behind their contracting by the intermediary. This might occur, for instance, in replacement or substitution contracts, where urgency constitutes the main determinant of addressing to a THA, or when client firms are not hiring for jobs where tested ability is important (i.e., unskilled jobs). In those cases, screening may not constitute the main added value in the provided services by the THA, since client firms are not searching for candidates on a permanent basis.

\section{Data and variables}

The data source we use are work histories of 19,778 individuals who may or may not be working for a THA in some moment of their work history. This information was collected from administrative data belonging to Social Security records. The database has information on all employment (and non-employment) spells of workers in the sample, from 1990 to $1999 .^{9}$ The work history data provided includes information about the age and gender of workers, the occupation held, ${ }^{10}$ the dates when the employment spell starts and ends, the type of Social Security system for the worker, the reason for the termination of the spell (voluntary quit, dismissal or retirement), the Spanish province where the employment spell took place, an identifier of whether each employment spell is accomplished through a THA or not and, finally, the type of contract held by the worker (temporary or permanent). In order to avoid capturing changes that are solely attributable to good or bad years, we also control for the economic cycle through the annual growth rate of the gross domestic product, and to mitigate the influence of geographical location we use both the regional unemployment rate and a dummy for

for the US labor market, Segal (1996) finds that personnel supply services workers are more educated, on average, than other hourly workers.

${ }^{9}$ Since in this database we cannot distinguish between unemployment and out of the labor force - the information we have is simply that workers are not employed at some point of their history - we address these spells as "non-employment".

${ }^{10}$ It must be underlined that the occupation indicates a level in a ranking determined by the worker's contribution to the Social Security. It is related to the individual's level of qualification, since it collects the required level of qualification for the job. However, it does not collect the workers' actual level of qualification but the level of qualification required for the job. For instance, an individual working in the lowest occupation may well be in possession of an academic degree. This caveat should be borne in mind throughout the subsequent analysis. 
the region where the employment takes place. ${ }^{11}$ The Appendix gives a complete description of the variables used in the estimation process.

We have dropped incomplete observations and kept only those workers affiliated to the General System (Régimen General) in order to circumvent the bias in our estimations that special systems like Agriculture, Fisheries, and so on would provoke. In order to achieve greater homogeneity, we also eliminate records that have terminated for reasons other than dismissals or ends of temporary contracts. ${ }^{12}$ Moreover, we wanted to focus both on changes in occupational levels and on transitions from temporary to permanent contracts. Therefore, we removed every observed transition where the initial contract did not consist of a temporary one. Finally, given that in order to identify our model we use a variable indicating the proportion of THA contracts over the total of labour contracts and that no data for this variable was available prior to 1995, we have restricted our sample to those employment spells beginning from 1995 onwards. Of the initial 19,778 individuals, selection of valid observations led us to a final sample of 13,571 individuals (or 56,048 spells).

Following the example of other studies using data from Social Security records, ${ }^{13}$ we have organized occupations into four groups: High, Upper-Intermediate, LowerIntermediate and Low Occupation. The specific categories within each group are detailed in the Appendix. We have also experimented with other ways of grouping the occupations. These alternative groupings also support our initial findings, although the results are to be seen most clearly when using our four-class classification. In addition, we have found that wage differences for this classification are also highly significant: $7.51 \%$ between the Low and Lower-Intermediate groups, $37.38 \%$ between the Lower-Intermediate and Upper-Intermediate groups, and $47.51 \%$ between the Upper-Intermediate and High ones. ${ }^{14}$ Therefore, we expect a change in occupations between these four groups to be a quite important fact in the economic situation of the worker.

In our data we have a variable identifying the actual employer in each employment spell along with information about whether or not each employment spell is accomplished through a THA ${ }^{15}$. Each observation in our data is represented by a worker's change of job, either with the same employer or a new one. This means that those individuals actually working through a THA may in the following spell

\footnotetext{
${ }^{11}$ Five zones are defined: Cataluña, Madrid, South, East and North.

${ }^{12}$ In this database we cannot distinguish between these two different reasons for termination of the spell.

${ }^{13}$ See, for instance, García-Fontes and Hopenhayn (1996), or García-Pérez (1997).

${ }^{14}$ We would like to thank Samuel Bentolila and Olympia Bover for providing us with this information.

${ }^{15}$ Each spell observed through a THA indicates in fact an employment contract with a client firm. However, we cannot identify whether after a THA spell, the worker begins working directly with the same client firm.
} 
go on working through the same THA, change to work through a new THA, or be hired by a non-THA employer. Similarly, those individuals working directly for a firm (i.e., without a THA as intermediary) may in the following spell go on working for the same employer or for a different one.

Sample characteristics for each occupation group are presented in Table 2. In the highest occupational level, THA workers are predominantly male (63.59\%) and are more likely to be under 30 years-old than their non-THA counterparts; from Table 2 we also obtain that THA workers in the highest occupational level are much more likely to downgrade their skill level when moving from one job to another one than non-THA workers (only $42.86 \%$ of THA workers kept their occupation constant when changing jobs, compared to $86.22 \%$ of non-THA workers). However, THA workers present an easier access to permanent contracts. In the two intermediate groups, THA workers are more likely to be women and also to be younger than non-THA workers. Moreover, THA workers in the UpperIntermediate group are slightly more likely than the other group of individuals to upgrade their occupational status when moving between different employment spells $(1.93 \%$ versus $1.80 \%)$ but less likely to find a permanent contract $(4.42 \%$ versus $6.95 \%$ ). Lower-Intermediate THA workers are more likely to maintain constant and avoid demotions than non-THA workers, but also less likely to achieve occupational upgrading or to get a permanent contract than their nonTHA counterparts. Finally, Table 2 shows that occupational transitions within the Low category group are not very common, and that, when they occur, the collective of non-THA workers enjoy relatively easier access to upward mobility.

\section{Econometric modelling}

We want to know to what extent, given an occupation of origin, THA-intermediated work increases the likelihood of upward occupational mobility. Occupational change is defined to occur either when the occupational category in two successive employment spells is different or when a transition from a temporary to a permanent contract is observed. This two-fold concept - focusing on the occupational category and the type of contract - allows us to study both the shifts along the occupational trajectory and the important issue of whether THAs make easier the transition to a permanent contract. Therefore, it allows us to make a distinction between the types of contract held, which are not identifiable through occupational categories or codes. Specifically, individuals' job-to-job transitions will be studied through the use of an ordered categorical dependent variable taking values from 0 to 3 , where value 0 represents the worst outcome - occupational demotion and both the actual contract and the following one are temporary - value 1 means maintaining the same occupational category and spells being temporary-temporary, value 2 reflects upward occupational mobility and 
spells being temporary-temporary, and, finally, value 3 represents a transition from a temporary contract to a permanent one no matter the change in the occupational level. Hence, we have estimated an ordered probit model on this dependent variable. ${ }^{16}$

However, we cannot simply consider the effect of working for a THA as only that of another explanatory variable in the ordered probit model, since individual self-selection is potentially a concern (as explained in Section 2 above). One of the main reasons for addressing to a THA is the likelihood of upward occupational mobility after leaving the THA that the individual can enjoy due to the screening role the latter is playing in the labor market. The individual earns wages by gaining employment through the THA and acquires both skills and an ability certification by the THA which can enhance the individuals' chances of achieving a better job after leaving the intermediary. The cost the individual must undergo through the THA assignment process consists of the risk of not passing the minimum ability level required in the tests implemented by the THA, and, in case he does, the uncertainty associated to the likelihood of receiving only brief assignments by the THA interspersed with relatively long periods of unemployment (Bronstein, 1991), or, for instance, the possibility of receiving lower wages than direct temporary hires by the client firm ${ }^{17}$. Therefore, individuals will only incur the costs associated to addressing to a THA if they think that after spending a part of their working life in a temporary assignment they can increase their chances of occupational upgrading, either through the access to a job with a higher occupational level or through eventually achieving a permanent contract. As a result, the unobservable characteristics which prompt individuals to apply to THAs may also be affecting their relative chances of promotion. Consequently, merely to control for the observable characteristics when explaining occupation changes is insufficient, since some additional process may be influencing those changes, namely, the factors that determine whether or not an individual works through a THA. The observed distribution of occupational changes will be influenced by this choice, and the use of standard regression techniques would lead to

\footnotetext{
${ }^{16} \mathrm{We}$ also estimated two different probit models, one for upward occupational mobility, and the other for downward occupational mobility across each job-to-job transition. Results do not significantly differ from the ones presented with the use of our ordered probit model. Moreover, although we have also applied an alternative multinomial specification, the hypothesis of independence of irrelevant alternatives is rejected.

${ }^{17}$ Applying to a THA to find a job may, therefore, imply an opportunity cost for the workers. For instance, Blank (1998) found that the median THA worker receives only 63 percent of the wage received by full-time workers. In this sense, it may well be the case that workers decide to apply to THAs only after direct methods to find a job have proved fruitless. Consequently, the group of THA workers may be those who inherently have more difficulty in finding jobs by themselves.
} 
inconsistent estimates of the parameters. ${ }^{18}$

In order to analyze this issue, we propose a switching model which describes the choice of THA work along with occupation transitions under the assumption that the assignment of individuals to the two groups is by self-selection rather than by random assignment. The model can be summarized by two equations: a selection equation and an occupation equation. The selection equation is given by:

$$
z^{*}=\beta_{s}^{\prime} x_{s}+u_{s}
$$

where $z^{*}$ is the difference between benefits and costs of addressing to a THA. A THA employment spell is observed if $z^{*}>0$, and a non-THA spell otherwise. Vector $x_{s}$ collects worker characteristics, and $u_{s}$ captures unobserved individual specific heterogeneity influencing both the decision of addressing to a THA and the one by the THA of hiring the worker.

The occupation equations - one for each possible selection choice - are given by:

$$
y_{k}^{*}=\beta_{c k}^{\prime} x_{c k}+u_{c k}, \quad k=0,1
$$

where $k=1$ denotes THA and $k=0$ denotes non-THA. ${ }^{19}$ That is, conditional on the individual's choice of THA versus non-THA work in each employment spell, occupational upgrading (i.e., a promotion through the occupational groups considered or through getting a permanent contract) may or may not be achieved. The choice of whether or not to apply to a THA enters endogenously into the occupation equations by estimating each equation conditional on the THA decision of the worker. This occupation equation is estimated by an ordered probit model with four possible outcomes depending on observed heterogeneity and the term $u_{c k}$ which captures the unobserved heterogeneity influencing the process of occupational mobility for both THA and non-THA workers. ${ }^{20}$ The different cutpoints for the ordered dependent variable are represented by $c_{1 j}$ and $c_{0 j}$ where $c_{10}$ and $c_{00}$ are set equal to zero.

However, if $x_{s}$ does not contain at least one element that is excluded from the occupation equations, the model is not well identified. ${ }^{21}$ Therefore, satisfactory

\footnotetext{
${ }^{18}$ To be more precise, not only the worker's decision of whether or not to address to a THA to find a job needs to be taken into account. In addition, the THA decision of whether or not to hire the worker is also relevant, given that we observe the worker in a THA spell only if she has actually been hired by the THA. However, the database has no available information on individuals who addressed to THAs but who were not finally hired by them.

${ }^{19}$ Each employment spell is independently considered for each individual. Hence, the same individual may have THA and non-THA observations.

${ }^{20}$ Imposing that unobserved heterogeneity in both THA and non-THA processes is the same does not change the results, although the unique correlation coefficient can be better identified in this latter case.

${ }^{21}$ Although, given the non-linearity of the model, it can also be just functionally identified.
} 
identification requires data on factors that affect the value of addressing to a THA but do not directly affect occupation transitions. We have selected one variable from labour statistics that, given worker's characteristics, we consider to be unrelated to occupation changes but is still related to the switching behavior. This variable is the proportion of THA assignment contracts in each province and year over the total of temporary contracts. Whether a worker does or does not apply to a THA may well be correlated with the relative importance of THA contracts in the relevant province (so that as this number increases, more workers are likely to consider those intermediaries as potential employers). In addition, it is unlikely for THA to locate in areas with the greatest fraction of "upward mobile" workers, since the decision of where to geographically locate the THA premises will be rather expected to depend on the volume of client firms' demand at each location. Therefore, in the analyses below, we include this variable as another determinant of the selection equation, but we exclude it from the occupation equations. ${ }^{22}$

Hence, the switching model can be rewritten as:

$$
\begin{aligned}
\text { THA: } y^{*}= & y_{1}^{*} \text { if } z^{*}>0 \\
\text { non-THA: } y^{*}= & y_{0}^{*} \text { if } z^{*} \leq 0 \\
\left(u_{c}, u_{s 1}, u_{s 0}\right) & \sim N(0, \Sigma)
\end{aligned}
$$

where $z^{*}, y_{1}^{*}$ and $y_{0}^{*}$ are given by equations (4.1) and (4.2) and $\Sigma$ is the covariance matrix of the error terms. As usual in switching models, we are able to estimate the correlation coefficient between $u_{s}$ and $u_{c 1}$ and between $u_{s}$ and $u_{c 0}$.

\section{Empirical results}

\subsection{Comments on estimates}

The estimations of the switching model for each occupational group are presented in Tables 3-6. The model with "endogenous THA use" accounts for self-selection, while the model with "exogenous THA use" imposes exogeneity of THA-intermediated work in the occupation equation - that is, it constrains the correlations between THA $\left(\rho_{s 1}\right)$ and non-THA $\left(\rho_{s 0}\right)$ error terms, respectively, and that of the selection equation to be equal to zero.

Some comments for the four groups of individuals can be made from the estimated selection equations. Age - a proxy for labor market experience- presents an important negative impact on the probability of working for a THA in any

\footnotetext{
${ }^{22}$ The predicted power of this instrumental variable is based on its variation across provinces and years. In fact, the coefficient of variation of this variable is larger than $53 \%$ in all the years considered.
} 
occupational group (except for the upper-intermediate one). That is, young people are much more likely to be working through THAs than other workers. As regard gender, THA workers are more likely to be men than women, except in the Upper-Intermediate occupation. However, the effect of gender changes with age. For instance, in the highest occupational group, it is only men under 41 years-old who are more likely to address THAs than women, while in the lowest category it is only men under 24 years-old who are relatively more attracted by THAs than women. In addition, workers in those Spanish provinces that have larger yearly proportions of THA contracts are more likely to work for THAs. Furthermore, workers are less likely to apply to THAs the larger the growth rate of the gross domestic product - which indicates that the THA business cycle dependence can be considered as countercyclical. The provincial unemployment rate has a significant positive impact for the two intermediate qualification groups -i.e., in provinces with higher unemployment, the likelihood of addressing to a THA is greater.

Occupation equations for each group reflect the impact of individual variables on the likelihood of occupational upgrading from the actual job to the following one. Estimated coefficients vary in both models due to the existence of endogeneity in the THA indicator. Given that for every qualification group at least one of the correlation coefficients between the selection and the occupation equations is significant, we keep attention only over the results which controls for endogenous THA use (Table 5).

Age has a positive impact on the likelihood of occupational upgrading (except for the lowest occupational group). Therefore, older workers are more likely to upgrade their occupation, that is, they are more likely to achieve steeper wage improvements. The age profile is concave. The effect of gender depends on most cases on age. For instance, THA men above 50 years-old in the LowerIntermediate group and those above 30 years-old in the Low group are more likely than similar women to enjoy better promotion prospects.

We have also included the duration of the non-employment spell between two jobs as an explanatory variable. Two effects may be at work here. On the one hand, those who - while unemployed - face more rapid skill depreciation, might be more likely to accept a job requiring a qualification level below the ones of previously-held jobs. On the other hand, staying more time unemployed may allow the worker to increase her ability to look for better jobs, so that the likelihood of better matches could be increasing with the duration of the unemployment spell. We find that the net effect, when significant, is negative for all workers but those in the Low qualification group. That is, the skill depreciation effect dominates for all workers but those in the lowest one. Moreover, except for the Lower-Intermediate group, the effect is even more negative for THA workers, which could be due to the fact that unemployment represents a bad signal for those individuals (see García-Pérez and Muñoz-Bullón, 2003). 
The effect of tenure on the job (i.e., the duration of the actual employment spell) is always positive, both for THA and non-THA individuals. As tenure in the current job increases, the accumulation of human capital can be larger and, therefore, the probability of upward occupational mobility is higher.

Looking at the unobserved characteristics, the signs of the correlations for selectivity allow us to draw interesting conclusions. The correction for sample selection gives a significant and positive estimate for the correlation coefficient in the occupation equation for THA workers in the High group. This indicates that expected occupational promotion of those highly qualified individuals who choose to work for a THA may be higher than that of a random individual from the entire sample for given characteristics. And, conversely, for THA workers in the Low occupational group the maximum likelihood gives a significant and negative sign for the correlation coefficient, which means that their expected occupational promotion prospects may be lower than the expected chances of upgrading for a random individual from the sample. There is, therefore, positive selection for THA workers in the highest occupational group and support for negative selection of THA workers in the lowest one. We return to this issue in the following section where we directly address the question whether individuals engaged through THAs would have performed as well as non-THA ones, had they decided to look for a job on their own.

\subsection{Expected occupational promotion chances and self-selection}

Interpretation of these results is easier by considering predicted probabilities of occupational upgrading (Tables $7 \mathrm{a}$ and $7 \mathrm{~b}$ ). Table 7a reports unconditional probabilities taking into account the self-selection problem, while Table $7 \mathrm{~b}$ does not. There are important differences between both models, which are attributed to the problem of self-selection. In the model with endogenous THA use, the likelihood of having to accept a new job with lower skill requirements is higher for non-THA workers but for the highest occupational group. However, a very important result is that the probability of attaining a permanent contract in this model is much larger for THA workers than for non-THA ones in the High occupational group: THA workers enjoy a $39.60 \%$ probability of achieving a permanent contract, as opposed to only $4.98 \%$ for non-THA ones. Another interesting finding is that not accounting for self-selection understates the differences between THA and non-THA workers in the High and Low groups: in the model with exogenous THA use, THA individuals in the High qualification category only attain permanent contracts with a $11.97 \%$ probability. Estimates of occupational promotion are also biased for the Low occupational groups when the potential self-selection is not taken into account, since non-THA workers only achieve permanent contracts with a $4.67 \%$ probability (as opposed to the $13.63 \%$ when correcting for 
self-selection) and keep constant their category with a $81.89 \%$ probability (as opposed to the corrected probability of $65.25 \%$ ).

Going one step further, we can work out what the predicted conditional probabilities would be, in order to study counterfactual scenarios. Our aim is to compare the probability of occupational upgrading of a THA worker conditional on having been engaged by a THA and its counterfactual, i.e., the probability of occupational upgrading if the worker had not been hired by a THA. Table 8 shows these estimated probabilities. In the first panel (Table 8a) the upgrading probabilities, conditional on having been hired by a THA, are presented; in the second panel (Table 8b) the ones conditional on not having been contracted by a THA are shown. In this table we have the contrafactual probability for a non-THA worker in the case she had been hired by a THA.

Upgrading and demotion probabilities of those hired by THAs can be compared to their counterfactuals. If we compare columns 1 and 2 in Table 8a, we observe that THA workers in the highest category group probably took the correct decision in choosing to work through a THA since - even though it would have been less likely to suffer a demotion (8.22\% as opposed to the actual $39.94 \%)$ - their probability of achieving a permanent contract is much higher than the one they would have enjoyed by working on their own (17.09\% as opposed to $10.06 \%$ ). A similar result is to be seen in the case of a non-THA worker (columns 1 and 2 in Table 8b): her probability of achieving a permanent contract would have been substantially larger if she had been hired through a THA (62.81\% as opposed to the actual 5.56\%). Moreover, non-THA individuals in this group would have more easily avoided movements down the skill ladder to an occupation requiring less skill than their previous occupation had they been hired through the intermediary (5.73\% as opposed to the actual $8.21 \%$ ).

As for THA workers in the Upper-Intermediate group, results are better than in case they had not been engaged by a THA, both in terms of exiting from a temporary contract and of avoiding occupational demotion (columns 3 and 4 in Table 8a). However, results are not so favorable for the counterfactuals of non-THA individuals in this occupational level (see columns 3 and 4 in Table $8 \mathrm{~b})$. Therefore, our predictions are not clear enough for this category level, a result which is also obtained when analyzing the Lower-Intermediate occupational group.

Finally, the performance of THA workers in the Low occupational group is always worse than that of non-THA ones. Had the former not addressed to the intermediary to look for a job, we note that both the counterfactual probability of achieving a permanent contract and that of occupational upgrading are substantially higher (16.09\% as opposed to the actual $1.26 \%$, and $23.28 \%$ as opposed to the actual $8.66 \%$, respectively). Moreover, the performance of non-THA workers in this occupational group would have been worse than in case they had been 
engaged through the intermediary. These results show that low-qualified THA workers are being negatively self-selected.

\section{Conclusion}

This paper has examined one of the patterns of occupational mobility related to THA work in Spain. In particular, our emphasis has been on the extent to which THA-intermediated work allows individuals to achieve occupational upgrading. Our empirical testing of the dynamics of workers' occupational level has been undertaken in such a way as to take into account the possible existence of selfselection into THA-intermediated work. That is, we have developed a switching model which allows us to examine the use of THAs along with occupational transitions across jobs under the possibility that the assignment of individuals to THA and non-THA work is by self-selection rather than by random assignment.

We have found evidence that highly-qualified workers are positively selected compared to non-THA ones in Spain. The benefits for being engaged through this intermediary translates into an easier access to permanent contracts for individuals in this highest occupational category. On the contrary, results also indicate the existence of negative self-selection among THA workers in the lowest qualification group. Had workers from this category not been hired by a THA, they would have enjoyed a higher likelihood of both accessing to permanent contracts and of avoiding occupational demotion.

Interpreting our results in the framework of the demand and supply-side motivations for addressing to a THA, the THA screening role appears as a relevant determinant for high-skilled individuals to address to a THA, though not among the lowest qualified ones. Among the latter, therefore, other motivations instead of the screening THA services are under the use of this intermediary. Although more detailed work is needed in this area, our results may help to promote a recognition of the social value of Temporary Help Agencies. Even though the present paper has not focused upon the satisfaction displayed by workers who are in this type of employment arrangement, on the amount of wages or fringe benefits they may be receiving, or on the actual level of provision of social protections for these THA workers, we have offered one reason why THA work should be recognized as a valid form of employment in its own right, albeit one that is substantially different to the standard employment relationship. In particular, we have found that THA work should not be entirely relegated to a second-class status where temporary workers are doomed to occupational stagnation, because of reduced opportunities of advancement or little opportunity to use their skills at the workplace. Although this may be true for certain types of workers, as a general statement about the entire labour market, it is simply not true. 


\section{Appendix: Occupation category groups and explana- tory variables}

The four category groups are the following: High Occupation collects the three highest levels in the ranking, that is, 1 (ingenieros and licenciados), 2 (ingenieros técnicos, peritos and ayudantes titulados) and 3 (jefes administrativos and de taller). Upper-Intermediate Occupation collects levels 4 (ayudantes no titulados), 5 (oficiales administrativos) and 6 (subalternos). Lower-Intermediate Occupation collects levels 7 (auxiliares administrativos) and 8 (oficiales de primera and segunda). Finally, Low Occupation collects levels 9 (oficiales de tercera and especialistas) and 10 (peones).

The explanatory variables used in this study are the following ones:

- Gender: 1 for men and 0 for women

- Age: age of the individual at the beginning of the employment spell

- Unemployment duration: length (in months) of the unemployment spell following the actual employment spell.

- Employment duration: length (in months) of the actual employment spell.

- \% THA contracts: percent proportion of the number of THA assignment contracts registered in each province and year corresponding to the beginning year of the employment spell.

- Gross domestic product (GDP) growth rate: for the selection (category) equations, this variable collects the yearly growth rate of the GDP for the beginning (ending) quarter of the employment spell.

- Unemployment provincial rate: for the selection (category) equations, this variable collects the unemployment rate for the province and the first quarter of the beginning (ending) year of the employment spell. 


\section{R eferences}

[1] Abraham, K. G. (1988). "Flexible Staffing Arrangements and Employers' Short-term Adjustment Strategies". In Robert E. Hart (ed.). Employment, Unemployment and Hours of Work. George Allen \& Unwin, London.

[2] Abraham, K. G.(1990) "Restructuring the Employment Relationship: The Growth of Market-Mediated Work Arrangements". In Katherine Abraham and Robert McKersie, eds. New Developments in the labour Market: Toward a New Institutional Paradigm Cambridge, Mass.: MIT Press, pp. 85-119.

[3] Autor, D. H. (2001). "Why Do Temporary Help Firms Provide Free General Skills Training?", Quarterly Journal of Economics, 116 (4), November, pp. 1409-1448.

[4] Ballantine, J. and R. Ferguson (1999). "labour Demand for Non-College Educated Young Adults", mimeo, Harvard University Kennedy School of Government.

[5] Belous, R.S. (1989). "How Human Resource Systems Adjust to the Shift Towards Contingent Workers", Monthly labour Review, vol. 109, pp. 7-12.

[6] Blank, R. M. (1998). "Contingent Work in a Changing labour Market". In Richard B. Freeman and Peter Gottschalk (eds.). Generating Jobs. How to Increase Demand for Less-skilled Workers. New York, Russell Sage Foundation, pp. 258-294.

[7] Bronstein, A.S. (1991). "Temporary Work in Western Europe — Threat or Compliment to Permanent Employment?". International Labour Review, vol. 130 (3), pp. 291-310.

[8] Cohany, S. R. (1996). "Workers in Alternative Employment Arrangements". Monthly labour Review, October, pp. 31-45.

[9] Cohany, S.R. (1998). "Workers in Alternative Employment Arrangements: A Second Look", Monthly labour Review, November, pp. 3-21.

[10] Davis-Blake, A. and B. Uzzi (1993). "Determinants of Employment Externalization: A Study of Temporary and Independent Contractors". Administrative Science Quarterly, vol. 38, pp. 195-223.

[11] Emerson, M. (1988). "Regulation or Deregulation of the Labour Market". European Economic Review, vol. 32, pp. 775-817. 
[12] García-Fontes, W. and H.Hopenhayn (1996). "Flexibilización y Volatilidad del Empleo". Moneda y Crédito, vol. 201, pp. 205-227.

[13] García-Pérez, J. I. (1997), "Las Tasas de Salida del Empleo y el Desempleo en España (1978-1993)", Investigaciones Económicas, XXI(1), pp. 29-53.

[14] García Pérez, J.I. and F. Muñoz Bullón (2003): "The Nineties in Spain: Too Much Flexibility in the Youth Labour Market?". Working Paper 03-03, Universidad Carlos III de Madrid, Madrid.

[15] Houseman, S.N. (1997). "Temporary, Part-Time and Contract Employment in the United States: New Evidence from an Employer Survey". W.E. Upjohn Institute for Employment Research, Kalamazoo, Mich.

[16] Mangum, G., D. Mayall and K. Nelson (1985). "The Temporary Help Industry: Response to the Dual labour Market".Industrial and labour Relations Review, vol. 38, pp. 599-611.

[17] Moberly, R.M. (1987). "Temporary, Part-Time and Other Atypical Employment Relationships in the United States". Labour Law Journal, November, pp. 689-696.

[18] Muñoz-Bullón, F. (2002). "La estrategia de subcontratación", in Bonache, J. and A. Cabrera (2002), Dirección Estratégica de Personas, Ed. Prentice-Hall, pp. $453-488$.

[19] Muñoz-Bullón, F. and E. Rodes (2003). "Temporalidad y Señalización en el Mercado de Trabajo: El Papel de las Empresas de Trabajo Temporal", forthcoming in Cuadernos de Economía y Dirección de la Empresa.

[20] Nollen, S.D. (1996). "Negative Aspects of Temporary Employment", Journal of labour Research, no. 4, Fall, pp. 567-582.

[21] Segal, L. (1996). "Flexible Employment: Composition and Trends". Journal of labour Research, vol. XVII, no. 4, pp. 525-542.

[22] Segal, L. and D. G. Sullivan (1997). "The Growth of Temporary Services Work". Journal of Economic Perspectives, vol. 11, no. 2, pp. 117-136.

[23] Steinberg, B. (1994). "1994 Profile of the Temporary Workforce", Contemporary Times, Spring.

[24] Steinberg, B. (1998). "1997 Profile of the Temporary Workfoce", Contemporary Times, Spring. 
[25] Tsui, A. S., Pearce, J.L., Porter, L.W., and Hite, J.P. (1995). "Choice of Employee-Organization Relationship: Influence of External and Internal Organizational Factors". Research in Personnel and Human Resource Management, 13: 117-151.

[26] Waldman, M.(1984) "Job Assignments, Signalling and Efficiency". Rand Journal of Economics, vol. 2, pp. 255-267. 
Table 1

Temporary contracts managed by THAs in Spain

\begin{tabular}{l|l|l|l} 
Year & $\begin{array}{l}\text { Temporary } \\
\text { contracts (1) }\end{array}$ & $\begin{array}{l}\text { Temporary contracts } \\
\text { managed by THAs (2) }\end{array}$ & $\begin{array}{l}\text { Proportion } \\
{[(2) /(1)]^{* 100}}\end{array}$ \\
\hline \hline 1995 & $5,519,350$ & 361,633 & $6.55 \%$ \\
1996 & $8,273,175$ & 748,601 & $9.05 \%$ \\
1997 & $9,386,084$ & $1,260,524$ & $13.43 \%$ \\
1998 & $10,692,315$ & $1,707,842$ & $15.97 \%$ \\
1999 & $12,017,063$ & $1,892,284$ & $15.75 \%$
\end{tabular}

Source: Spanish Ministry of Labor 
Table 2

M ain sample characteristics

\begin{tabular}{l|c|c|c|c|c|c|c|c} 
& \multicolumn{2}{|c|}{$\begin{array}{c}\text { High } \\
\text { Occupation }\end{array}$} & \multicolumn{2}{c|}{$\begin{array}{c}\text { U pper-interm. } \\
\text { Occupation }\end{array}$} & \multicolumn{2}{c}{$\begin{array}{c}\text { Lower-interm. } \\
\text { Occupation }\end{array}$} & \multicolumn{2}{c}{ Low } \\
Occupation
\end{tabular}

N otes: The values in the top row indicate the number of spells in each occupation (but not individuals). All variables are proportions with respect to the first row except Empl. Dur. and Unempl. Dur. which represent the mean duration, in days, of the actual employment spell studied and of the intermediate spell of non-employment between this and the following employment spell. 
Table 3

Estimation results for the Selection Equation with endogenous THA

use ( $\mathrm{t}$-ratios in parentheses)

\begin{tabular}{l|c|c|c|c} 
& High & $\begin{array}{c}\text { Upper- } \\
\text { Intermediate }\end{array}$ & $\begin{array}{c}\text { Lower- } \\
\text { Intermediate }\end{array}$ & Low \\
\hline Constant & $8.148(5.66)$ & $4.732(9.96)$ & $2.467(12.36)$ & $2.925(16.17)$ \\
Gender:Male & $2.882(5.91)$ & $-1.865(-10.42)$ & $0.277(3.45)$ & $0.549(8.07)$ \\
Gender*Age & $-0.070(-4.57)$ & $-2.756(-9.15)$ & $-0.023(-8.74)$ & $-0.023(-10.41)$ \\
Age & $-5.881(-6.95)$ & $0.398(8.10)$ & $-2.439(-19.16)$ & $-1.331(-11.73)$ \\
Age & $0.879(6.57)$ & $0.459(6.48)$ & $0.405(19.47)$ & $0.195(10.87)$ \\
$\%$ THA Contracts & $6.830(2.41)$ & $11.118(2.90)$ & $8.791(15.66)$ & $2.471(5.16)$ \\
GDP growth rate & $-0.138(-1.73)$ & $-0.018(-3.96)$ & $-0.138(-9.01)$ & $-0.170(-12.63)$ \\
Unempl. provincial rate & $0.004(0.36)$ & $0.050(8.57)$ & $0.041(22.14)$ & $-0.001(-0.38)$
\end{tabular}

Notes: Equations also include dummies for the specific occupations within each of the four groups.

Table 4

Estimation results for the Selection Equation with exogenous THA use ( $\mathrm{t}$-ratios in parentheses)

\begin{tabular}{l|c|c|c|c} 
& High & $\begin{array}{c}\text { Upper- } \\
\text { Intermediate }\end{array}$ & $\begin{array}{c}\text { Lower- } \\
\text { Intermediate }\end{array}$ & Low \\
\hline Constant & $8.056(5.66)$ & $4.749(10.01)$ & $2.479(12.41)$ & $2.929(16.17)$ \\
Gender: Male & $2.873(5.90)$ & $-1.883(-10.55)$ & $0.279(3.46)$ & $0.542(7.96)$ \\
Gender*Age & $-0.069(-4.53)$ & $-2.759(-9.19)$ & $-0.023(-8.76)$ & $-0.023(-10.35)$ \\
Age & $-5.742(-6.86)$ & $0.398(8.13)$ & $-2.443(-19.94)$ & $-1.338(-11.77)$ \\
Age & $0.857(6.49)$ & $0.464(6.53)$ & $0.405(19.50)$ & $0.196(10.89)$ \\
\% THA Contracts & $6.098(2.10)$ & $11.103(2.88)$ & $8.720(15.49)$ & $2.520(5.16)$ \\
GDP growth rate & $-0.172(-2.16)$ & $-0.018(-4.02)$ & $-0.137(-8.95)$ & $-0.172(-12.74)$ \\
Unempl. provincial rate & $0.003(0.31)$ & $0.051(8.72)$ & $0.041(22.05)$ & $-0.0001(-0.04)$
\end{tabular}

Notes: Equations also include dummies for the specific occupations within each of the four groups. 


\section{Table 5}

\section{Estimation results for the Occupation Equation with endogenous}

THA use ( $\mathrm{t}-$ ratios in parentheses)

\begin{tabular}{l|c|c|c|c|} 
& High & $\begin{array}{c}\text { U pper- } \\
\text { Intermediate }\end{array}$ & $\begin{array}{c}\text { Lower- } \\
\text { Intermediate }\end{array}$ & Low \\
\hline THA workers & $-8.928(-4.12)$ & $-1.751(-1.85)$ & $-0.214(-0.73)$ & $0.099(0.37)$ \\
Constant & $-0.505(-0.45)$ & $-0.619(-1.24)$ & $-0.402(-3.59)$ & $-1.166(-10.09)$ \\
Gender: Male & $-0.002(-0.05)$ & $0.021(1.43)$ & $0.008(1.89)$ & $0.039(9.54)$ \\
Gender*Age & $6.214(4.40)$ & $1.635(2.32)$ & $0.995(4.32)$ & $-0.471(-2.81)$ \\
Age & $-0.902(-4.114)$ & $-0.260(-2.44)$ & $-0.141(-3.70)$ & $0.020(0.75)$ \\
Age & $-0.025(-0.62)$ & $-0.103(-6.83)$ & $-0.009(-2.82)$ & $0.063(11.44)$ \\
Unemployment duration & $0.045(2.89)$ & $0.039(9.34)$ & $0.053(15.01)$ & $0.052(9.96)$ \\
Employment duration & $0.231(1.77)$ & $0.044(0.88)$ & $0.081(3.72)$ & $-0.077(-3.82)$ \\
GDP growth rate & $-0.011(-0.61)$ & $-0.004(-0.45)$ & $-0.009(-2.42)$ & $-0.008(-2.57)$ \\
Unempl. provincial rate & $1.3076(4.43)$ & $2.434(35.44)$ & $3.121(78.53)$ & $0.953(31.09)$ \\
Threshold $c_{1}$ & - & $2.636(35.12)$ & $3.561(74.06)$ & - \\
Threshold $c_{11}$ & $0.609(2.09)$ & $0.063(0.19)$ & $-0.153(-1.26)$ & $-0.623(-4.16)$ \\
$\rho_{s 1}$ N on-THA workers & & & & \\
Constant & $-1.436(-0.63)$ & $-2.041(-2.30)$ & $-0.288(-0.62)$ & $1.308(2.19)$ \\
Gender: Male & $-0.176(-0.20)$ & $0.794(2.67)$ & $-0.343(-2.61)$ & $-0.659(-3.78)$ \\
Gender*Age & $0.005(0.21)$ & $-0.025(-2.84)$ & $0.007(1.55)$ & $0.023(3.62)$ \\
Age & $1.485(1.02)$ & $1.430(3.07)$ & $0.718(2.66)$ & $-0.794(-3.27)$ \\
Age ${ }^{2}$ & $-0.197(-0.87)$ & $-0.203(-2.86)$ & $-0.108(-2.42)$ & $0.086(2.21)$ \\
Unemployment duration & $-0.072(-5.78)$ & $-0.050(-7.82)$ & $-0.056(-11.17)$ & $0.017(3.03)$ \\
Employment duration & $0.048(8.11)$ & $0.052(11.06)$ & $0.042(14.24)$ & $0.053(12.17)$ \\
GDP growth rate & $0.170(2.15)$ & $0.094(2.49)$ & $0.099(4.08)$ & $-0.045(-1.71)$ \\
Unempl. provintial rate & $-0.015(-1.92)$ & $0.004(0.82)$ & $0.001(0.33)$ & $-0.012(-4.26)$ \\
Threshold $c_{0}$ & $3.126(33.06)$ & $2.194(22.32)$ & $2.610(64.23)$ & $0.704(14.06)$ \\
Threshold $c_{01}$ & - & $2.326(22.39)$ & $2.979(63.15)$ & - \\
$\rho_{s 0}$ & $-0.127(-0.29)$ & $0.351(1.69)$ & $-0.155(-1.31)$ & $-0.459(-2.99)$ \\
\hline M ean Log Likelihood & -0.833295 & -1.38937 & -1.17454 & -1.01537 \\
Size & 1,560 & 4,761 & 21,778 & 27,949 \\
\hline
\end{tabular}

N otes: Equations also include dummies for the occupations within each of the four groups, and for geographical zones (reference category: Madrid). 
Table 6

Estimation results for the Occupation Equation with exogenous THA

use ( $\mathrm{t}$-ratios in parentheses)

\begin{tabular}{l|c|c|c|c|} 
& High & $\begin{array}{c}\text { U pper- } \\
\text { Intermediate }\end{array}$ & $\begin{array}{c}\text { Lower- } \\
\text { Intermediate }\end{array}$ & Low \\
\hline THA workers & $-7.647(-3.09)$ & $-1.613(-2.35)$ & $-0.083(-0.304)$ & $-0.201(-0.71)$ \\
Constant & $0.833(0.94)$ & $-0.711(-2.71)$ & $-0.379(-3.44)$ & $-1.396(-12.94)$ \\
Gender: Male & $-0.036(-1.23)$ & $0.024(2.67)$ & $0.006(1.57)$ & $0.049(12.82)$ \\
Gender*Age & $4.737(3.14)$ & $1.523(3.44)$ & $0.811(4.76)$ & $-0.230(-1.30)$ \\
Age & $-0.689(-2.93)$ & $-0.244(-3.39)$ & $-0.110(-3.97)$ & $-0.018(-0.64)$ \\
Age & $-0.025(-0.54)$ & $-0.103(-6.87)$ & $-0.010(-2.82)$ & $0.069(12.76)$ \\
Unemployment duration & $0.056(4.55)$ & $0.039(9.33)$ & $0.053(15.17)$ & $0.059(11.30)$ \\
Employment duration & $0.233(1.58)$ & $0.040(0.83)$ & $0.076(3.48)$ & $-0.053(-2.49)$ \\
GDP growth rate & $-0.005(-0.24)$ & $-0.005(-0.72)$ & $-0.007(-2.14)$ & $-0.007(-2.27)$ \\
Unempl. provincial rate & $1.540(9.60)$ & $2.437(40.01)$ & $3.139(125.94)$ & $1.014(39.41)$ \\
Threshold $c_{1}$ & - & $2.639(38.97)$ & $3.583(117.15)$ & - \\
Threshold $c_{11}$ & & & & \\
\hline N on-THA workers & & $-0.824(-1.54)$ & $0.157(0.49)$ & $-0.168(-0.48)$ \\
Constant & $-1.942(-1.53)$ & $-0.435(2.11)$ & $-0.319(-2.43)$ & $-0.928(-7.07)$ \\
Gender: Male & $-0.367(-0.73)$ & $0.005(1.14)$ & $0.033(7.78)$ \\
Gender*Age & $0.010(0.63)$ & $-0.015(-2.28)$ & $0.005)$ \\
Age & $1.794(2.25)$ & $0.895(2.59)$ & $0.489(2.37)$ & $-0.369(-1.71)$ \\
Age 2 & $-0.244(-1.91)$ & $-0.126(-2.28)$ & $-0.070(-2.06)$ & $0.019(0.58)$ \\
Unemployment duration & $-0.073(-5.98)$ & $-0.052(-8.21)$ & $-0.056(-11.19)$ & $0.019(3.35)$ \\
Employment duration & $0.048(8.04)$ & $0.053(12.25)$ & $0.042(15.47)$ & $0.058(21.02)$ \\
GDP growth rate & $0.174(2.19)$ & $0.083(2.13)$ & $0.093(3.77)$ & $-0.004(-0.16)$ \\
Unempl. provintial rate & $-0.016(-2.01)$ & $-0.001(-0.21)$ & $0.004(1.49)$ & $-0.012(-4.02)$ \\
Threshold $c_{0}$ & $3.132(38.24)$ & $2.265(52.30)$ & $2.630(100.83)$ & $0.766(36.16)$ \\
Threshold $c_{01}$ & - & $2.402(51.27)$ & $3.002(97.03)$ & - \\
\hline M ean Log Likelihood & -0.834192 & -1.39001 & -1.17469 & -1.01559 \\
Size & 1,560 & 4.761 & 21,778 & 27,949 \\
\hline
\end{tabular}

N otes: Equations also include dummies for the occupations within each of the four groups, and for geographical zones (reference category: Madrid). 
Table 7a:

Occupation equation: Unconditional Predictions for M odel with Endogenous THA use

\begin{tabular}{l|c|c|c|l|c|l|l|l|} 
& \multicolumn{2}{|c|}{ High } & \multicolumn{2}{c|}{ Upper+nterm. } & \multicolumn{2}{c|}{ Lower-nter. } & \multicolumn{2}{c|}{ Low } \\
\hline & No THA & THA & No THA & THA & No THA & THA & No THA & THA \\
Permanent & 4.98 & 39.60 & 4.40 & 3.64 & 3.39 & 2.39 & 13.63 & 0.63 \\
Upgrading & - & - & 1.38 & 1.93 & 3.87 & 3.80 & 21.10 & 5.52 \\
= Qualif. & 88.06 & 45.57 & 67.47 & 74.44 & 80.31 & 88.12 & 65.25 & 93.85 \\
Demotion & 6.95 & 14.82 & 26.74 & 19.99 & 12.42 & 5.69 & - & - \\
\hline
\end{tabular}

Table 7b:

Occupation equation: Unconditional Predictions for Model with Exogenous THA use

\begin{tabular}{l|c|l|c|l|c|l|c|l|} 
& \multicolumn{2}{|c|}{ High } & \multicolumn{2}{c|}{ U pper+nter. } & \multicolumn{2}{c|}{ Lower+nter. } & \multicolumn{2}{c|}{ Low } \\
\hline \hline & No THA & THA & No THA & THA & No THA & THA & No THA & THA \\
Permanent & 4.72 & 11.97 & 5.97 & 3.19 & 4.43 & 1.88 & 4.67 & 0.91 \\
Upgrading & - & - & 1.79 & 1.74 & 4.73 & 3.21 & 13.43 & 8.00 \\
= Qualif. & 88.06 & 52.24 & 72.31 & 73.47 & 81.15 & 88.27 & 81.89 & 91.08 \\
Demotion & 7.22 & 35.78 & 19.91 & 21.59 & 9.69 & 6.63 & - & - \\
\hline
\end{tabular}

N ote: Predicted probabilities are calculated by holding all variables at their sample mean. 
Table 8a:

Occupation equation: Conditional predictions for THA workers

\begin{tabular}{l|c|c|c|c|c|c|c|c|} 
& \multicolumn{2}{|c|}{ High } & \multicolumn{2}{c|}{ U pper-4nter. } & \multicolumn{2}{c|}{ Lower-nter. } & \multicolumn{2}{c|}{ Low } \\
\hline & $\operatorname{Pr}\left(y_{N E}\right)$ & $\operatorname{Pr}\left(y_{E}\right)$ & $\operatorname{Pr}\left(y_{N E}\right)$ & $\operatorname{Pr}\left(y_{E}\right)$ & $\operatorname{Pr}\left(y_{N E}\right)$ & $\operatorname{Pr}\left(y_{E}\right)$ & $\operatorname{Pr}\left(y_{N E}\right)$ & $\operatorname{Pr}\left(y_{E}\right)$ \\
Permanent & 10.06 & 17.09 & 1.97 & 4.29 & 4.41 & 3.39 & 16.09 & 1.26 \\
Upgrading & - & - & 0.66 & 1.99 & 4.51 & 4.58 & 23.28 & 8.66 \\
= Qualif. & 81.71 & 42.97 & 55.73 & 70.46 & 79.85 & 86.80 & 60.61 & 90.08 \\
Demotion & 8.22 & 39.94 & 41.63 & 23.24 & 11.22 & 5.23 & - & - \\
\hline
\end{tabular}

Table 8b:

Occupation equation: Conditional predictions for non- $\mathrm{THA}$ workers

\begin{tabular}{l|c|c|c|c|c|c|c|c|} 
& \multicolumn{2}{|c|}{ High } & \multicolumn{2}{c|}{ Upper-nter. } & \multicolumn{2}{c|}{ Lower-4nter. } & \multicolumn{2}{c|}{ Low } \\
\hline & $\operatorname{Pr}\left(y_{N E}\right)$ & $\operatorname{Pr}\left(y_{E}\right)$ & $\operatorname{Pr}\left(y_{N E}\right)$ & $\operatorname{Pr}\left(y_{E}\right)$ & $\operatorname{Pr}\left(y_{N E}\right)$ & $\operatorname{Pr}\left(y_{E}\right)$ & $\operatorname{Pr}\left(y_{N E}\right)$ & $\operatorname{Pr}\left(y_{E}\right)$ \\
Permanent & 5.56 & 62.81 & 6.89 & 4.67 & 2.90 & 2.29 & 5.74 & 0.13 \\
Upgrading & - & - & 1.85 & 2.13 & 3.26 & 3.30 & 13.64 & 1.78 \\
= Qualif. & 86.21 & 31.46 & 70.36 & 71.33 & 77.73 & 85.88 & 80.61 & 98.08 \\
Demotion & 8.21 & 5.73 & 20.89 & 21.86 & 16.09 & 8.53 & - & - \\
\hline
\end{tabular}

N ote: Predicted probabilities are conditional in each panel on working through a THA and not doing so, respectively. The contrafactual probabilities are in italics. 